\title{
Lumps in the thigh
}

\author{
Mark S. Igra ${ }^{1}$ - James D. Thomas ${ }^{2}$
}

Published online: 2 April 2016

(C) ISS 2016

\section{Case}

A 39 year old woman presented with a 5 month history of a painless lump in the medial aspect of her right thigh. MR imaging was performed and is shown in the figures Figs. 1, 2 and 3.

What is the diagnosis?

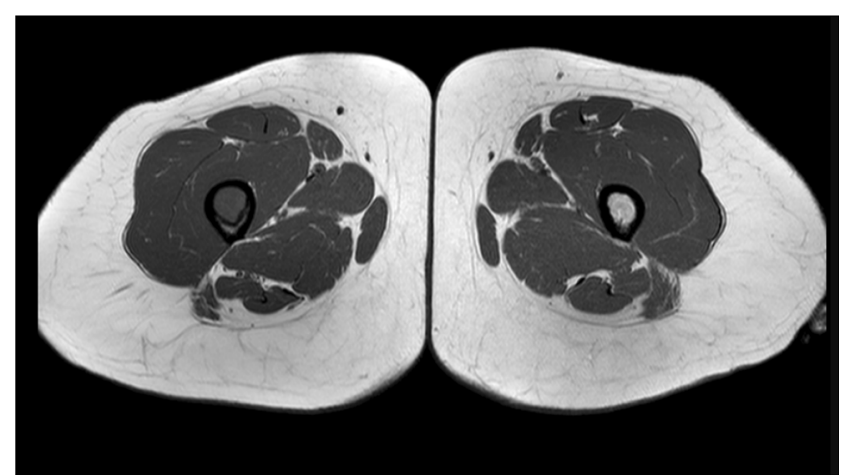

Fig. 1 Axial T1W MRI at mid-thigh

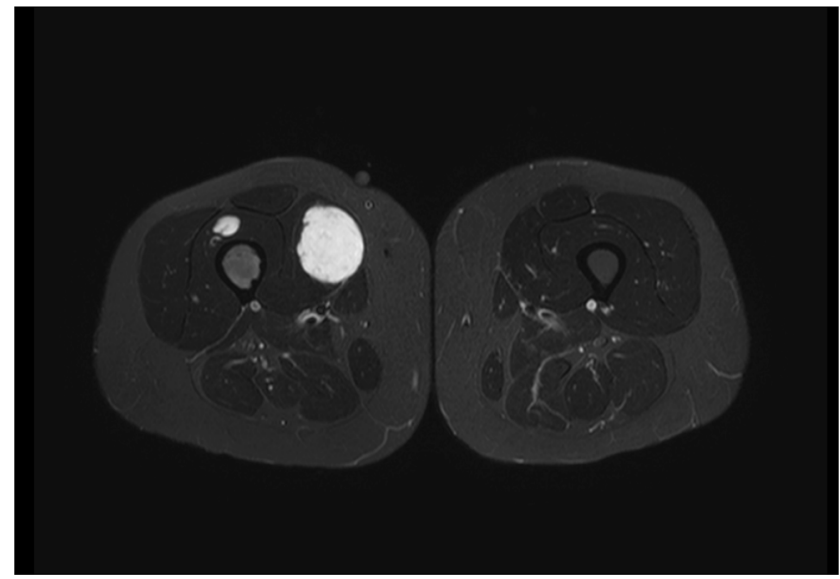

Fig. 2 Axial fat-saturated T2W MRI at mid-thigh 


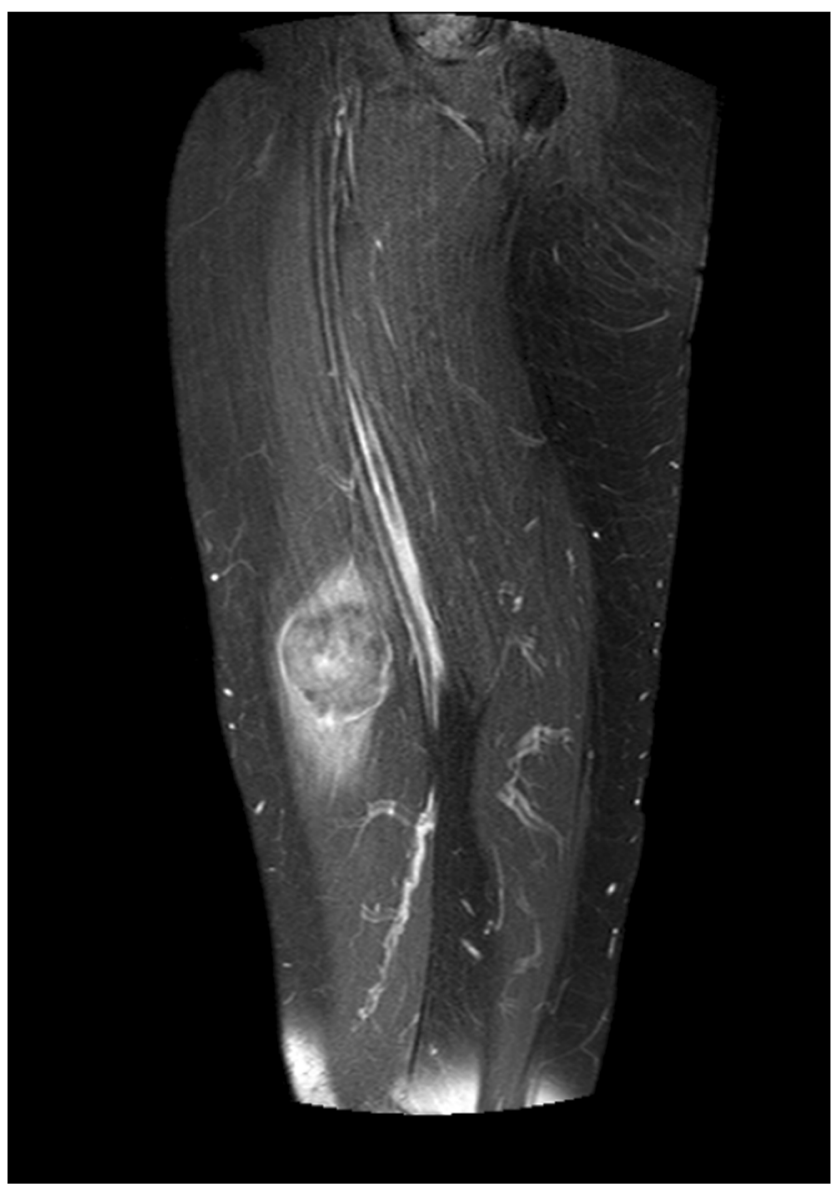

Fig. 3 Sagittal post-Gd fat-saturated T1W MRI, anterior right thigh

\section{Compliance with ethical standards}

Conflict of interest The authors declare that they have no conflict of interest. 